\title{
Visfatin, Omentin -1 and lipid profile in patients with psoriasis and their relation to Disease severity
}

\author{
Abdelraheem TA ${ }^{(1)}$, Ali SA ${ }^{(2)}$, Mohamed SR ${ }^{(3)}$ and Mohamed HA ${ }^{(4)}$. \\ (1) professor of Dermatology, STDs and andrology department, Faculty of Medicine \\ Fayoum Universty. \\ (2) Lecturer of Dermatology, STDS and Andrology, Faculty of Medicine, Fayoum \\ University. \\ (3) Lecturer of Biochemistry, Faculty of Medicine, Fayoum University. \\ (4) Department of Dermatology, Faculty of Medicine Fayoum University.
}

Corresponding author: prof .Talal A. Abd-ElRaheem

E-mail address: talasam@yahoo.com

Tel:01006600360

Fax: +2 084636583

\begin{abstract}
Psoriasis is a chronic, autoimmune, and inflammatory disease of unknown etiology. The association of the novel adipokines visfatin and omentin- 1 with psoriasis is still obscure. Data concerning other inflammatory diseases suggest a possible role of these adipokines in the pathophysiology of psoriasis. The present study represents a retrospective case-control study carried on 28 patients with plaque-type psoriasis and 30 healthy controls، serum and tissue visfatin and omentin-1 levels were measured by using the ELISA technique. Our results showed that Serum

KEY WORDS: Psoriasis, visfatin, omentin-1, lipid profile.

\section{INTRODUCTION}

Psoriasis is a common chronic inflammatory skin condition that varies in Severity, It is characterized by hyperproliferation and altered differentiation of keratinocytes, T lymphocytes infiltration, and vascular changes (1). Adipose tissue is known
\end{abstract}

\section{PATIENTS AND METHODS}

The present case control study included 28 patients with psoriasis vulgaris and and tissue levels of visfatin in psoriasis group were significantly higher than controls

( $\mathrm{p}$-value $=0.001,0.04$ respectively). There was a significant positive correlation between serum $=$ and tissue visfatin levels and PASI score $(\mathrm{r}$ $p=0.003$ and $r=0.39, p=0.001$. Serum omentin- 1 level was significally lower in patients group than controls ( $\mathrm{p}$-value $=0.017$ ). Also, LDL was significally higher $(\mathrm{p}$-value $=0.029)$,

HDL was significally lower in psoriasis group than controls ( $\mathrm{p}$-value $=0.001)$.

to be an active endocrine organ regulating body metabolism by secretion of metabolically important proteins alled adipokines, csuch as leptin, adiponectin , visfatin, and omentin(2). visfatin has several proinflammatory and immune-modulating properties(3). decreased omentin level was reported in several proinflammatory states(4)

of samples at $2000 \mathrm{x} \mathrm{g}$ for 10 minutes was done and sera were separated and stored at $-20^{\circ} \mathrm{C}$ 
28 healthy controls, recruited from the

Dermatology Clinic, Faculty of

Medicine, Fayoum University. This study was

conducted during the time

interval from August 2016 to January 2017.

Peripheral venous blood samples were

withdrawn from 30 patients after

fasting for 12 hours. Serum samples were

collected into a serum separator

tube. After clot formation, centrifugation until analysis. Lipid profile

(cholesterol, triglycerides, HDL and LDL)

was estimated immediately after collection of serum .

Visfatin and omentin-1 were estimated

by ELISA. A skin punch instrument with a

blade extends through to the fat to obtain a

cylindrical specimen from the psoriatic plaque lesions.

The skin biopsies were stored in an

eppendorf at $-70^{\circ} \mathrm{C}$ for ELISA examination for tissue visfatin and omentin-1.

\section{RESULTS}

1- There was a statistically significant difference between cases and controls as regards serum and tissue visfatin levels with high mean of serum and tissue visfatin among cases.

\begin{tabular}{|l|c|c|c|c|c|c|}
\hline \multirow{2}{*}{ Variables } & \multicolumn{2}{|c|}{ Case $(\mathrm{n}=28)$} & \multicolumn{2}{c|}{ Control $(\mathrm{n}=28)$} & \multirow{2}{*}{ p-value } & \multirow{2}{*}{ Sig. } \\
\cline { 2 - 6 } & Mean & SD & Mean & SD & & \\
\hline Visfatin & 3.42 & 0.56 & 2.49 & 0.55 & $\mathbf{0 . 0 0 1}$ & HS \\
\hline Serum & 4.1 & 1.4 & 3.5 & 0.67 & $\mathbf{0 . 0 4}$ & S \\
\hline Tissue &
\end{tabular}

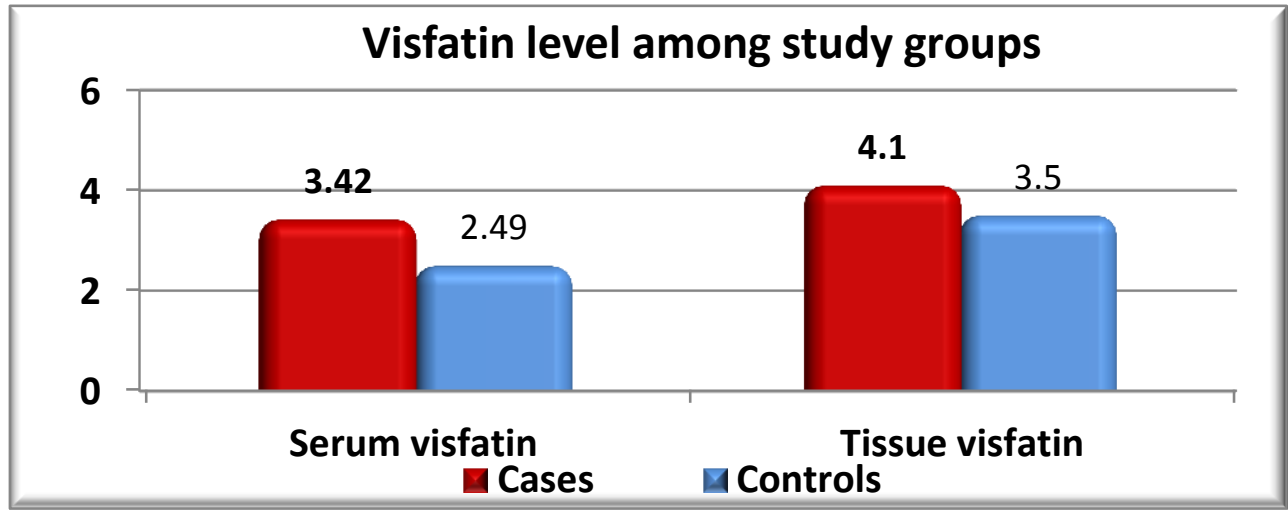

2- There was a statistically significant difference between cases and controls as regards serum omentin-1 level with low mean of serum omentin-1 among cases

\begin{tabular}{|c|c|c|c|c|c|c|}
\hline \multirow{2}{*}{ Variables } & \multicolumn{2}{|c|}{ Case $(\mathrm{n}=28)$} & \multicolumn{2}{c|}{ Control $(\mathrm{n}=28)$} & \multirow{2}{*}{ p-value } & \multirow{2}{*}{ Sig. } \\
\cline { 2 - 5 } & Mean & SD & Mean & SD & & \\
\hline Serum omentin1 & 31.1 & 2.6 & 39.79 & 19.2 & $\mathbf{0 . 0 1 7}$ & S \\
\hline Tissue omentin1 & 39.1 & 4.8 & 37.7 & 4.8 & 0.27 & NS \\
\hline
\end{tabular}




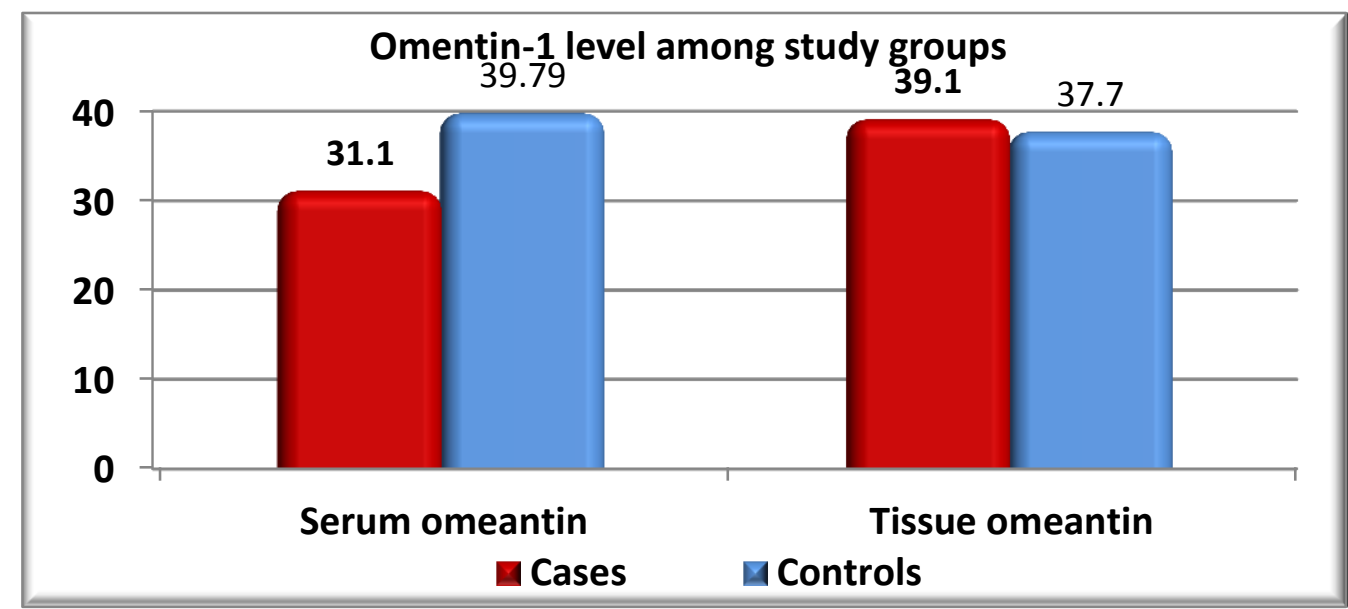

3- There was a statistically significant positive correlation with $\mathrm{p}$-value $<0.05$ between serum visfatin and PASI score which represents disease severity .

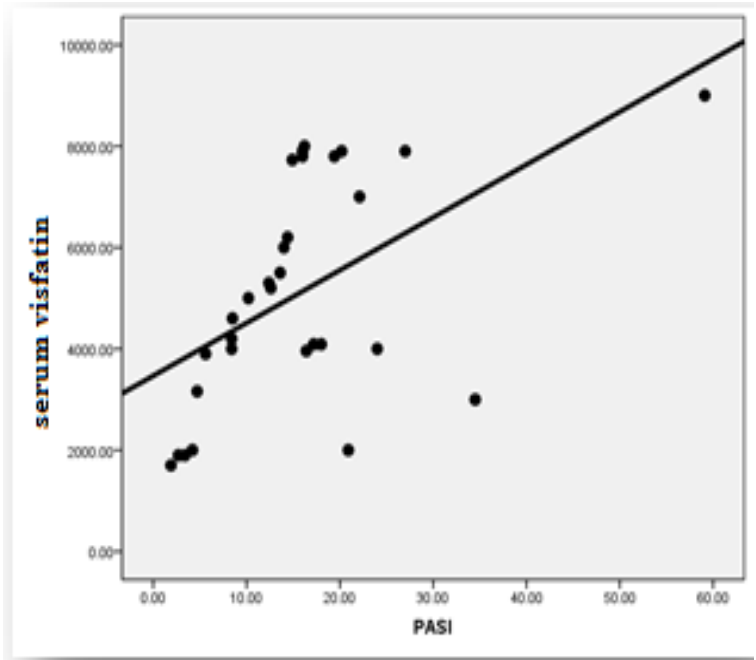

4- There was a statistically significant positive correlation between tissues visfatin and PASI score which represents disease severity .

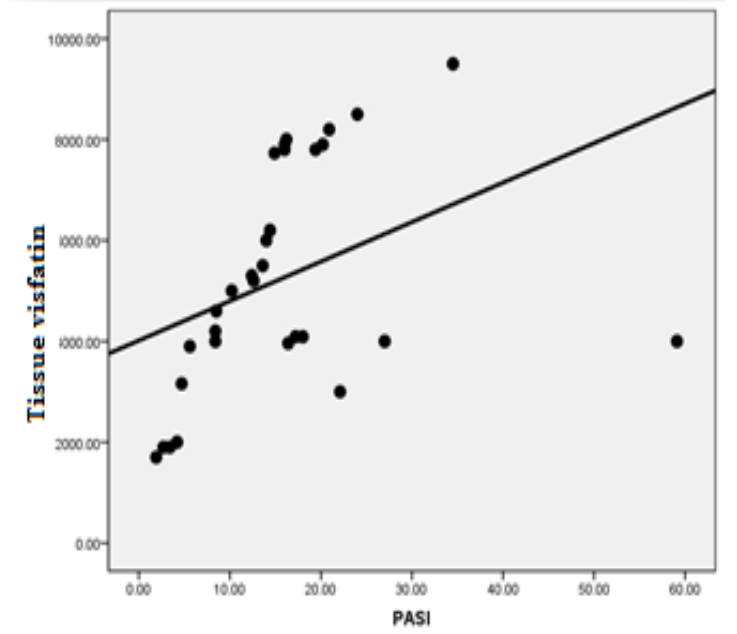




\section{DISCUSSION}

Psoriasis is a chronic, immune-, mediated hyperproliferative, and inflammatory skin disease of varying severity. The genetic, immunological and environmental factors contribute to the pathogenesis of The psoriasis. pathological mechanism in psoriasis involves cutaneous inflammation and keratinocytes hyperproliferation induced by an inflammatory cascade in dermis involving innate and adaptive immune cells(5). The role of visfatin in psoriasis might include modulation of the inflammatory or immune response as it induces chemotaxis and increases the production of IL-1, IL-6, TNF- $\alpha$, and + costimulatory molecules by CD14 monocytes. This enhances their ability to induce proliferative responses (3).

Our results revealed a statistically significant difference between patients and controls regarding serum and tissue visfatin with high mean among psoriasis patients $(\mathrm{p}=0.001, \mathrm{p}=0.04$ respectively), and there was a statistically significant positive correlation between PASI score and both of serum $(\mathrm{r}=0.53, \mathrm{p}=0.003)$ and tissue visfatin $(\mathrm{r}=0.39, \mathrm{p}=0.001)$.

\section{CONCLUSION}

Serum and tissue visfatin levels are increased in psoriasis patients and serum omentin-1 level is decreased and lipid profile is altered (high LDL, low HDL)
There was a statistically significant difference $(p<0.05)$ between both groups regarding serum omentin1 with low mean among psoriasis patients $(\mathrm{p}=0.017)$. Also there was a statistically significant difference between patients and controls as regards HDL ( $p$-value $=0.001$ ) with low mean among patients and LDL

( $p$ value $=0.029$ ) with high mean among patients. Our results were in agreement with

\section{‘.Ismail et al., 2012, Badran et al}

\section{4 ،Okan et al., 2016 and Zu Elfakkar et al., 2017} who reported that the serum level of visfatin in psoriatic patients was statistically

significantly higher than the serum level of visfatin in the controls and there was a positive

significant correlation between the serum level of visfatin and the PASI score. In agreement with Taheri et al., 2014, we found that LDL were significantly higher in the patients group and HDL were significantly lower in the patients group compared to the controls. Serum omentin-1 levels were significantly lower in psoriasis patients compared to controls $(p=0.017)$ that was in line with Zhang et al., 2015 results who confirmed a significant decrease in serum omentin-1 levels in patients with psoriasis compared with healthy controls.

and visfatin levels were positively correlated with PASI score which refer to possible role of these findings in pathogenesis of psoriasis and potential cardiovascular comorbidity. 


\section{REFERENCES}

\section{[1] Krueger G and Ellis CN (2005):}

Psoriasis - recent advances in understanding its pathogenesis and treatment. J Am Acad Dermatol; 53: 94100.

\section{[2]Antuna-Puente B, Feve B, Fellahi $S$} and Bastard JP (2008): Adipokines the missing link between insulin resistance and obesity. Diabetes Metab؛ 34(1): 2-11.

\section{[3] Luk T, Malam Z and Marshall JC} (2008): Pre-B cell colony-enhancing factor (PBEF) / visfatin: a novel mediator of innate immunity. J Leukoc Biol 83(4): 804816.

\section{[4] Tan BK, Adya R and Randeva HS} (2010): Omentin, a novel link between inflammation, diabesity, and cardiovascular disease. Trends Cardiovasc Med; 20(5): 143-148.

\section{[5] Ismail SA and Mohamed SA}

(2012):Serum levels of visfatin and omentinin patients with psoriasis and their relation to disease severity. British J Dermatol; 167(2): 436-439.
[6]Badran FK, Genedy RM, Swelem RS and AlRawi MZ (2014): Evaluation of serum level of visfatin among psoriatic patients. Egypt J. Dermatol Venerol; 34(2):107-113.

[7]Okan G, Baki AM, Yorulmaz E, Dogru-Abbaso $S$ and Vural P (2016): Serum visfatin, fetuin-A and pentraxin-3 levels in patients with psoriasis and their relation to disease severity. J Clin Lab Anal; 30(4): 284-289.

[8]Zu Elfakkar N M, Asaad M K, Abdul Wahab A, Ezz H (2017): Serum level of Visfatin in Psoriasis and its Relation to Disease Severity. Egyptian J. Hosp Med; 69(1): 1558-1562.

\section{[9]Taheri SM, Hedayati MT, Shokohi T and} HajHeydari Z (2014): Serum lipids and lipoproteins in patients with psoriasis. Arch Iran Med; 17(5): 343346.

[10]Zhang C, Zhu KJ, Liu JL, Xu GX, Liu W, Jiang FX, Zheng HF and Quan C (2015): Omentin-1 plasma levels and omentin- 1 expression are decreased in psoriatic lesions of psoriasis patients. Arch Dermatol Res; 307(5): 455-459. 